\title{
SPATIOTEMPORAL TRENDS OF CASES OF PANDEMIC INFLUENZA A(H1N1)PDM09 IN ARGENTINA, 2009-2012
}

Carlos M. LEVEAU(1), Osvaldo UEZ(1) \& Marta N. VACCHINO(1)(2)

\begin{abstract}
SUMMARY
The aim of this paper was to analyze the spatiotemporal variations of cases of influenza A(H1N1)pdm09 in Argentina. A space-time permutation scan statistic was performed to test the non-randomness in the interaction between space and time in reported influenza A(H1N1)pdm09 cases. In 2009, two clusters were recorded in the east of Buenos Aires Province (May and June) and in the central and northern part of Argentina (July and August). Between 2011 and 2012, clusters near areas bordering other countries were registered. Within the clusters, in 2009, the high notification rates were first observed in the school-age population and then extended to the older population (15-59 years). From 2011 onwards, higher rates of reported cases of influenza A(H1N1)pdm09 occurred in children under five years in center of the country. Two stages of transmission of influenza A(H1N1)pdm09 can be characterized. The first stage had high rates of notification and a possible interaction with individuals from other countries in the major cities of Argentina (pattern of hierarchy), and the second stage had an increased interaction in some border areas without a clear pattern of hierarchy. These results suggest the need for greater coordination in the Southern Cone countries, in order to implement joint prevention and vaccination policies.
\end{abstract}

KEYWORDS: Influenza A(H1N1)pdm09; Cluster analysis; Spatiotemporal analysis; Argentina.

\section{INTRODUCTION}

In April 2009, the first cases of influenza A(H1N1)pdm09 were discovered in Mexico and California (USA). At the end of that year, the new virus had caused, at least, 18,000 deaths ${ }^{14}$. Unlike what happened in these countries, the arrival of the influenza $\mathrm{A}(\mathrm{H} 1 \mathrm{~N} 1) \mathrm{pdm} 09$ in the Southern Hemisphere coincided with the period of circulation of seasonal influenza. In Argentina, the first cases of influenza A(H1N1) pdm09 were detected in early May, registering a peak circulation of the virus in late June ${ }^{18}$. Compared with other countries in the Southern Hemisphere, Argentina recorded the highest rates of mortality from influenza $\mathrm{A}(\mathrm{H} 1 \mathrm{~N} 1) \mathrm{pdm} 09^{18}$.

There are very few studies that analyze the spatiotemporal interactions of cases of influenza A(H1N1)pdm09. Furthermore, these studies were conducted primarily in developed countries and have focused only on the dynamics of 2009, the first year of the appearance of the virus $6,10,13,19,20$. After the first year of the onset of influenza $\mathrm{A}(\mathrm{H} 1 \mathrm{~N} 1)$ pdm09, there have been new outbreaks in some countries (New Zealand ${ }^{2}$, the United Kingdom ${ }^{5}$ and Mexico ${ }^{3}$ ). However, since the emergence of the virus, no studies have thus far been conducted to analyze the spatial-temporal trends in the medium term.

A more detailed study on patterns of the intranational spatial spread of the virus would raise new hypotheses about the factors that influence its rapid circulation. Moreover, this would allow more effective design policies for prevention and control measures in the context of a significant increase in demand on health systems.

The aim of this paper is to analyze the spatiotemporal variations of cases of influenza A(H1N1)pdm09 in Argentina, between 2009 and 2012.

\section{MATERIAL AND METHODS}

Data collected by the National Surveillance System based on Laboratories (SIVILA) were used. Health establishments present in all provinces of Argentina reported to this system. More detailed information on the monitoring system can be found in VAN KERKHOVE et al. ${ }^{18}$

All laboratory confirmed cases of pandemic influenza A(H1N1) pdm09 between 2009 and 2012 that were confirmed with registered information about a department of residence were evaluated.

The spatial units were composed of the 509 departments that make up the Argentine territory, and the autonomous city of Buenos Aires. Figure 1 shows the 24 jurisdictions that comprise the Argentine territory.

In addition, age and sex were recorded when available. In 2009,

(1) Instituto Nacional de Epidemiología “Juan H. Jara”, ANLIS Malbrán. Ituzaingo 3520, (7600) Mar del Plata, Argentina.

(2) Facultad de Ciencias Exactas y Naturales. Universidad Nacional de Mar del Plata, Argentina.

Correspondence to: Carlos M. Leveau, Tel.: +54 0223493 7347. E- mail: cmleveau@ hotmail.com 


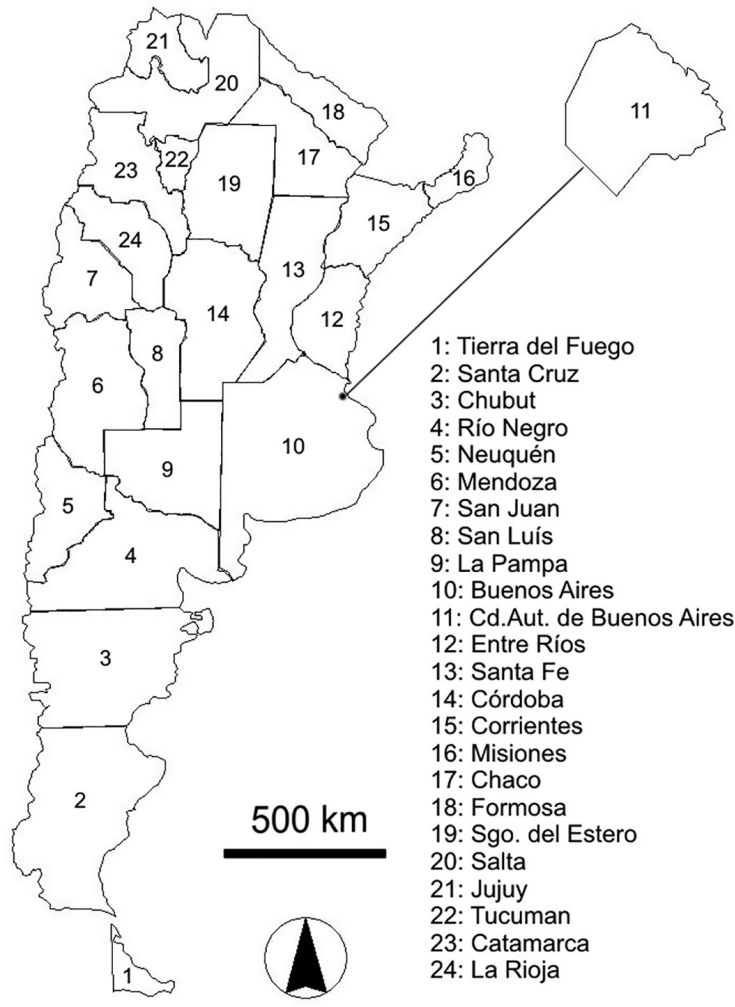

Fig . 1 - The Autonomous City of Buenos Aires and Provinces of Argentina.

$66.2 \%$ and $70.2 \%$ of the reported cases had data on age and sex, respectively. In 2011, this percentage was $97.2 \%$ for both variables, while in $2012,85.9 \%$ and $73.1 \%$ were the respective totals for this information. Notified cases were divided into six age groups $(0-4,5-14,15-29,30-44$, 45-59 and $60+$ years) and two groups according to sex. For each age and sex group, population data from the 2010 Census $^{7}$ were used as the denominator for notification rates. Because there are no population data by age group and sex for the years 2009, 2011 and 2012, data from the 2010 census were used as the denominator of the rates over the years.

Cluster definition: the general concept of cluster means a more heterogeneous 'clumped' distribution of disease cases than would be expected from the variation in population density and chance fluctuations ${ }^{1}$. A space-time permutations scan statistic was conducted to test the non-randomness in the interaction between the space and time of the recorded cases of influenza $\mathrm{A}(\mathrm{H} 1 \mathrm{~N} 1) \mathrm{pdm} 09^{8,9}$. This analysis consists of thousands of cylinders that move through the different points (formed by the geographic center of each department). Each cylinder has a base, which represents the geographical area, and a height, which is the time (in this case, the unit of time is the month). The base of each cylinder comprised a maximum of $50 \%$ of the population, while the height was a maximum period of six months. The cylinder with more observed cases than expected, with respect to the cases reported outside the cylinder, is called 'cluster 1' (or 'most likely cluster'). The expected number of cases was estimated assuming complete spatial-temporal randomness, which is synonymous with assuming a constant risk (Poisson) distribution. Since the space-time permutation scan statistic requires only case data, for each department and month the expected cases were calculated as the proportion of all cases that occurred in a department (' $x$ ') times the total number of cases during month ('y'). The expected number of cases in each cylinder is the summation of every department's expected cases that comprised that cylinder ${ }^{8}$. The space-time permutation scan statistic also calculates secondary clusters. To test the hypothesis of the nonrandom location of these clusters, 9999 Monte Carlo permutations were performed. If the Poisson generalized likelihood ratio of the 'cluster 1' (or other secondary clusters) exceeds $5 \%$ of the maximum ratios calculated by permutations, the cluster is significant at $p<0.05$. The space-time scan statistic was performed separately for each year.

The SaTScan version 9.1.1 software developed by Martin Kulldorff, Harvard Medical School (Boston, USA) and the Information Management Services Inc (Maryland, USA) was used.

\section{RESULTS}

The year 2009 had the highest viral circulation, with 9007 reported cases of influenza A(H1N1)pdm09 in Argentina. During this year, there were two space-time clusters: the main cluster was located in the eastern part of the province of Buenos Aires, during the months of May and June, while the secondary cluster was located in centralnorthern Argentina, without occupying the provinces of Entre Rios, Corrientes and Misiones, during the months of July and August (Table 1, Fig. 2). In 2010, the lowest number of cases $(n=14)$ was reported and no space-time clusters were detected. In 2011, the number of cases increased $(n=160)$ and there were two clusters: the first, between the months of May and July, was located in central-western Argentina, mainly occupying the provinces of Mendoza, San Juan and San Luis, while the second cluster was located in the north of the country during the months of September and November (Table 1, Fig. 3). Finally, 2012 showed the highest number of cases $(n=341)$ recorded after 2009, the year of the onset of the virus in Argentina. There were three clusters: the first was recorded in northern Argentina, between February and July, the second cluster was located in the center-west, between the months of September and October, and the third cluster was located in the northeast of the country, mainly in the province of Corrientes, during the month of August (Table 1, Fig. 4).

Tables 2 and 3 show the rates of notifications of influenza H1N1 in each spatial-temporal cluster. In 2009, within cluster 1 there were higher rates of notifications of influenza $\mathrm{A}(\mathrm{H} 1 \mathrm{~N} 1) \mathrm{pdm} 09$ in the young population (0-14 years) and lower rates in the older population (60+) compared to the other age groups. Cluster 2 showed lower rates in the age groups: 5-14, 60 and older, compared to the other groups. When comparing the two clusters, lower rates were observed in children under 14 years and a higher rate in the group aged 15 to 29 in cluster 2 (Table 2). No differences between sexes (Table 3 ) were observed.

In 2011, there was a significantly higher rate of notifications in individuals under five years compared to other age groups in cluster 1 (Table 2). There was also a higher rate in men as compared to women in cluster 1 but not in cluster 2. In cluster 2 there were no large variations between notification rates by age and gender groups.

In 2012, only cluster 2 showed a higher rate of notifications in the age group under five years compared to all other age groups, meanwhile cluster 1 showed higher rates for the 30-44, 45-59 and $60+$ age groups (Table 2). In cluster 3 , there were also higher rates of notification in 
Table 1

Characteristics of clusters of cases of influenza A(H1N1)pdm09 in Argentina, 2009-2012

\begin{tabular}{cccccc}
\hline & Period (months) & Observed cases & Expected cases & Test statistic & $p$ \\
\hline Year 2009 & & & & & \\
Cluster 1 & May-June & 2093 & 1442.77 & 157.22 & $<0.001$ \\
Cluster 2 & July-August & 1779 & 1207.01 & 139.60 & $<0.001$ \\
Year 2011 & & & & $<0.001$ \\
Cluster 1 & May-July & 64 & 28.48 & 21.61 & $<0.001$ \\
Cluster 2 & September-November & 72 & 37.03 & 18.43 & $<0.001$ \\
Year 2012 & & & & $<0.001$ \\
Cluster 1 & February-July & 49 & 11.64 & 35.28 & $<0.001$ \\
Cluster 2 & September-October & 75 & 35.64 & 19.09 & 12.54 \\
Cluster 3 & August & 102 & 63.64 & & \\
\hline
\end{tabular}

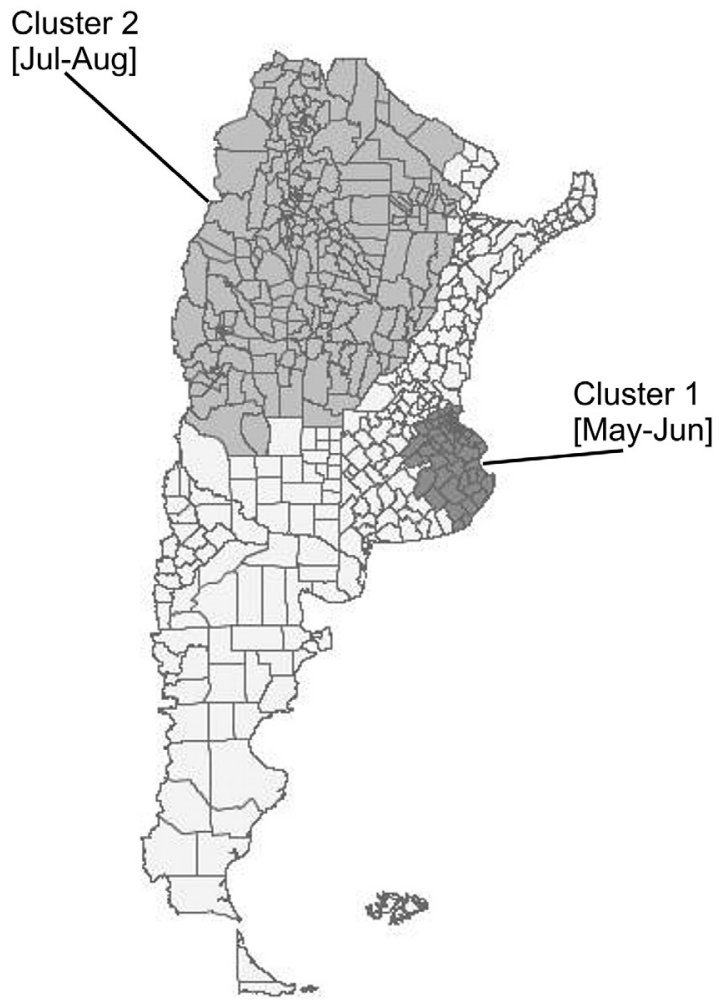

Fig. 2 - Spatiotemporal clusters of cases of Influenza A H1N1 in Argentina, 2009. Months within brackets.

individuals under five years, compared to the 5-14, 45-59 and $60+$ age groups (Table 2). In the three clusters, there was no difference between the rates by sex. In general, notification rates by age group and sex were higher in cluster 3 than in clusters 1 and 2.

\section{DISCUSSION}

Spatiotemporal variations were observed in cases of influenza A(H1N1)pdm09 in Argentina between 2009 and 2012, and the

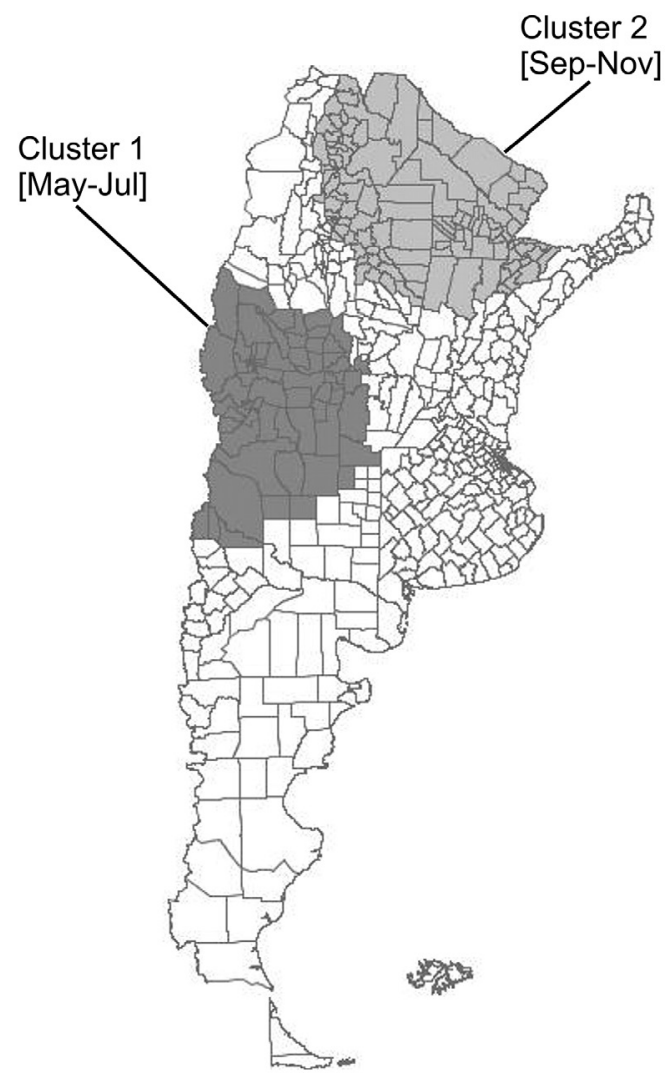

Fig. 3 - Spatiotemporal clusters of cases of Influenza A H1N1 in Argentina, 2011. Months within brackets.

spatiotemporal clusters showed differences in the composition of age groups.

There was a difference between the spatiotemporal pattern recorded in 2009, the year of the emergence of influenza A(H1N1)pdm09, and the patterns found between 2011 and 2012. In May and June of 2009, cluster 1 was located around agglomerate Buenos Aires, the main entrance of individuals from countries in the Northern Hemisphere to 


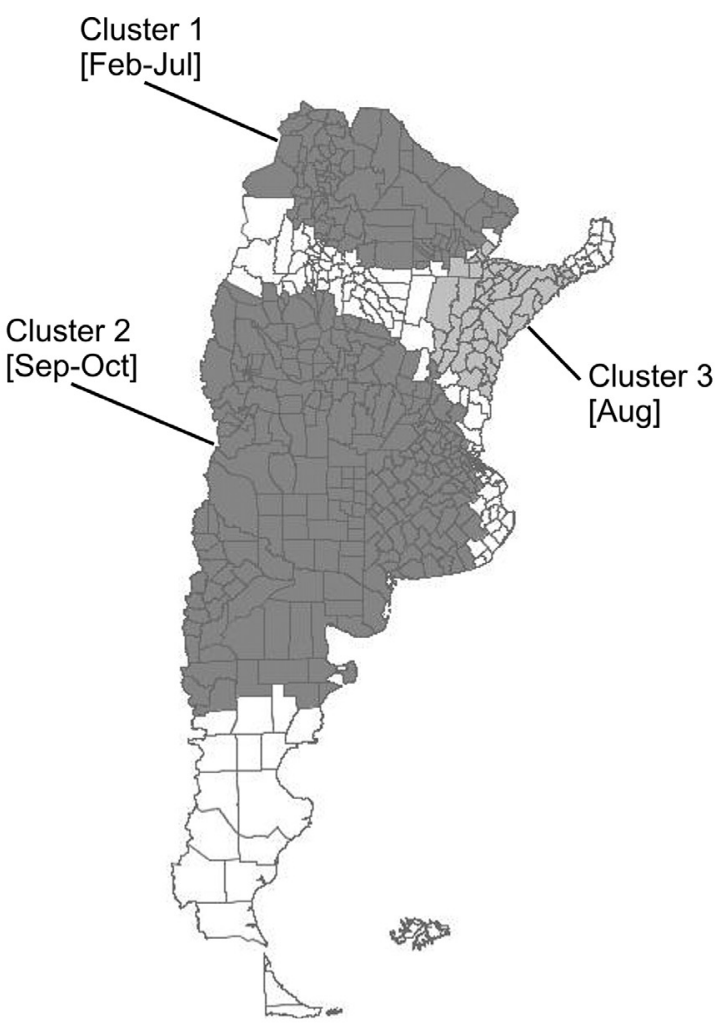

Fig. 4 - Spatiotemporal clusters of cases of Influenza A H1N1 in Argentina, 2012. Months within brackets.

South America, through Ezeiza International Airport, and south-east of the province of Buenos Aires. Between the months of July and August, there was another cluster in north-central Argentina, apart from the Mesopotamian provinces located to the east of the country (Entre Rios, Corrientes and Misiones). This cluster 2 comprised six of the 10 largest cities of Argentina, according to the 2001 Census. Apparently, the spatiotemporal distribution of cases of influenza A(H1N1)pdm09 followed a hierarchical pattern along the settlement system in 2009. After a year with very few cases, there was a change in the location of spatiotemporal clusters between 2011 and 2012, now being distributed near the border areas with neighboring countries. In 2011, the location of cluster 1, which comprises the provinces of Mendoza and San Juan, could be related to an abrupt increase in cases of influenza $\mathrm{A}(\mathrm{H} 1 \mathrm{~N} 1)$ pdm09 in Chile since epidemiological week (EW) $27(n=48)^{16}$. The location of cluster 2, in northern Argentina, during the months of October and November, coincided with a peak of confirmed cases $(n=343)$ in southern Bolivia (data from Santa Cruz) for EW 39 (end of September) and the emergence of cases of influenza A(H1N1)pdm09 in Paraguay between epidemiological weeks 42 and 46 (October and November) ${ }^{16}$.

In 2012, there was also a relationship between increased cases registered in Santa Cruz de la Sierra (southern Bolivia) during February and June, and a peak of cases in Paraguay during the last week of June and the spatial-temporal cluster located in northern Argentina, in February and July ${ }^{16}$. The duration of cluster 1 was unusually long when compared to that of the other clusters. The relationship with the two outbreaks in the two bordering countries can be related to the unusual length of cluster 1 . The outbreak observed in Paraguay could also be related to the spatiotemporal cluster mainly located in Corrientes, during the month of August. In the case of cluster 2, located in the center of the country and bordering Chile, there appears to be no interaction because there were very few cases in this country. It is likely that there could be a transmission of cases from cluster 3, recorded in August, to cluster 2, with cases observed between September and October.

These spatiotemporal changes between 2009 and 2011-2012 correspond to a transition of transmission of influenza A(H1N1)pdm09 in two stages. The first stage is characterized by an interaction with individuals from Northern Hemisphere countries through major cities of Argentina (hierarchical transmission). The second stage is characterized by greater interaction in some border areas without a clear pattern of hierarchical transmission. Related to this, in the coastal area of Peru, the first outbreak occurred in 2009, which included the major metropolitan area of the country

Table 2

Reported cases of influenza A(H1N1)pdm09 per 100000 inhabitants (2010 Census) by age group, Argentina 2009-2012

\begin{tabular}{|c|c|c|c|c|c|c|c|c|c|c|c|c|}
\hline & \multicolumn{2}{|c|}{$0-4 \mathrm{yr}$} & \multicolumn{2}{|c|}{$5-14 \mathrm{yr}$} & \multicolumn{2}{|c|}{$15-29 \mathrm{yr}$} & \multicolumn{2}{|c|}{$30-44 \mathrm{yr}$} & \multicolumn{2}{|c|}{$45-59 \mathrm{yr}$} & \multicolumn{2}{|c|}{$60+y r$} \\
\hline & Rate & $95 \% \mathrm{CI}$ & Rate & $95 \% \mathrm{CI}$ & Rate & $95 \% \mathrm{CI}$ & Rate & $95 \% \mathrm{CI}$ & Rate & $95 \% \mathrm{CI}$ & Rate & $95 \% \mathrm{CI}$ \\
\hline \multicolumn{13}{|l|}{2009} \\
\hline Cluster 1 & 23.80 & $21.25-26.57$ & 17.23 & $15.67-18.90$ & 10.94 & 09.94-12.00 & 11.82 & $10.70-13.01$ & 12.40 & $11.09-13.82$ & 6.06 & $5.16-7.07$ \\
\hline Cluster 2 & 12.29 & $10.40-14.44$ & 8.13 & $7.06-9.31$ & 13.43 & $12.24-14.71$ & 13.85 & $12.47-15.34$ & 12.60 & $11.09-14.27$ & 5.21 & $4.22-6.38$ \\
\hline \multicolumn{13}{|l|}{2011} \\
\hline Cluster 1 & 6.64 & $4.22-9.97$ & 2.38 & $1.38-3.84$ & 1.46 & $0.81-2.43$ & 1.42 & $0.72-2.54$ & 0.56 & $0.14-1.53$ & 0.20 & $0.01-0.98$ \\
\hline Cluster 2 & 2.79 & $1.65-4.44$ & 0.62 & $0.29-1.18$ & 1.09 & $0.66-1.69$ & 1.44 & $0.87-2.26$ & 1.40 & $0.76-2.38$ & 0.30 & $0.05-0.99$ \\
\hline \multicolumn{13}{|l|}{2012} \\
\hline Cluster 1 & 3.19 & $1.73-5.42$ & 1.44 & $0.78-2.45$ & 1.23 & $0.69-2.06$ & 0.79 & $0.32-1.65$ & 0.56 & $0.14-1.52$ & 0.48 & $0.08-1.59$ \\
\hline Cluster 2 & 1.60 & $1.02-2.41$ & 0.26 & $0.12-0.52$ & 0.20 & 0.09-0.39 & 0.38 & $0.21-0.64$ & 0.58 & $0.33-0.95$ & 0.47 & $0.25-0.82$ \\
\hline Cluster 3 & 9.30 & $5.98-13.86$ & 2.02 & $1.06-3.52$ & 4.78 & $3.36-6.60$ & 4.14 & $2.63-6.21$ & 3.05 & $1.65-5.19$ & 0.98 & $0.25-2.66$ \\
\hline
\end{tabular}


Table 3

Reported cases of influenza A(H1N1)pdm09 per 100000 inhabitants (2010 Census) by sex group, Argentina 2009-2012

\begin{tabular}{rcccc}
\hline & Female & \multicolumn{3}{c}{ Male } \\
\cline { 2 - 5 } & Rate & $95 \%$ CI & Rate & $95 \%$ CI \\
\hline 2009 & & & & \\
Cluster 1 & 12.77 & $12.02-13.55$ & 12.70 & $11.93-13.51$ \\
Cluster 2 & 13.48 & $12.62-14.37$ & 12.19 & $11.36-13.06$ \\
2011 & & & & \\
Cluster 1 & 1.10 & $0.69-1.67$ & 2.39 & $1.75-3.20$ \\
Cluster 2 & 1.04 & $0.73-1.45$ & 1.40 & $1.03-1.87$ \\
2012 & & & & \\
Cluster 1 & 0.94 & $0.59-1.45$ & 1.38 & $0.93-1.98$ \\
Cluster 2 & 0.42 & $0.29-0.58$ & 0.52 & $0.37-0.69$ \\
Cluster 3 & 3.50 & $2.61-4.60$ & 4.16 & $3.16-5.37$ \\
\hline
\end{tabular}

(Lima) in June ${ }^{4}$. This outbreak mainly affected children of school age. In July, the outbreak was dispersed to the rest of Peru, affecting all age groups ${ }^{4}$. The southernmost provinces of Argentina have not shown space-time clusters. However, it has been found that colder and drier temperatures, as recorded in these regions, increase the transmission of influenza virus ${ }^{6,11}$. There may be other spatial and sociodemographic factors affecting the circulation of influenza $\mathrm{A}(\mathrm{H} 1 \mathrm{~N} 1)$ pdm09. The increase in public transport use or a younger population structure has been associated with higher incidences and hospitalizations due to influenza A(H1N1)pdm09 ${ }^{12,20}$. These Patagonian provinces are characterized by low population densities and relatively large buffers between the main urban centers. These spatial and socio-demographic factors could play a more important role in the transmission of influenza $\mathrm{A}(\mathrm{H} 1 \mathrm{~N} 1)$ pdm09. Furthermore, the results analyzed in this study seem to suggest that the seasonality of influenza A(H1N1)pdm09 appears to be similar to other types and subtypes of flu virus in Argentina ${ }^{16}$.

In 2009, while in cluster 1 (May-June) the highest rates of notifications were recorded in individuals under 15, in cluster 2 (July to August) rates were similar in most age groups, but with lower reporting rates in the 5-14 and 60+ age groups. This significant decrease in the first age group could reflect the role that school closures could have had on the level of transmission in the school population. This strategy has had a positive effect on the reduction of cases of influenza $A(H 1 N 1)$ pdm09 pandemic in Tierra del Fuego, at the southern end of Argentina ${ }^{15}$.

Except in 2010, the clusters located in the center of the country reported higher rates of case notification of influenza A(H1N1)pdm09 in children under five years compared to other age groups, while during 2011 and 2012, there were no differences in notification rates between age groups and sexes between clusters located in northern Argentina.

The highest notification rates in children under five years are consistent with data analyzed by BANDARANAYAKE et al. ${ }^{2}$, who found higher rates of hospitalization for influenza A(H1N1)pdm09 in children under five years in New Zealand, during the two outbreaks of
2009 and 2010. This skewed distribution towards younger individuals agrees with the hypothesis of an extended immunization of older adults, born before 1969, exposed to any of the three pandemics during the first half of the twentieth century ${ }^{3,17}$. On the other hand, in Mexico, the proportion of hospitalizations for influenza A(H1N1)pdm09 was higher in older individuals in an outbreak in 2011-2012 compared to $2009^{3}$.

This study has some limitations, mainly due to the quality of the data used and the strategy for obtaining the samples used by the health system. Regarding the quality, in areas of lower population density and less access to clinical virological laboratories the number of notifications could have been underestimated. However, SIVILA (Sistema Nacional de Vigilancia por Laboratorios) already had sentinel units in all provinces of Argentina in 2009. Concerning sampling strategies, this was changed in mid-June 2009, when the sampling of severe cases was prioritized. This change may also have affected the spatiotemporal patterns recorded in 2009. In addition, other studies are needed to describe the spread of the virus through genetic and antigenic data.

In conclusion, this study's results suggest important spatial and temporal variations in notifications of influenza $\mathrm{A}(\mathrm{H} 1 \mathrm{~N} 1) \mathrm{pdm} 09$ in Argentina, that pose the need for greater coordination in the Southern Cone countries at the time of carrying out the policies of prevention and vaccination.

\section{RESUMEN}

\section{Tendencias espacio-temporales en los casos de gripe A(H1N1)pdm09 en Argentina, 2009-2012}

El objetivo de este trabajo es analizar las variaciones espaciotemporales de los casos de gripe A(H1N1)pdm09 en Argentina. Se realizó un escaneo estadístico espacio-temporal por permutaciones para poner a prueba la no aleatoriedad en la interacción entre espacio y tiempo de los casos registrados de gripe A(H1N1)pdm09. Durante 2009 se identificaron dos conglomerados espacio-temporales, en el este de la provincia de Buenos Aires (mayo y junio) y en la mayor parte del centro-norte de la Argentina (julio y agosto). Durante 2011 y 2012 se registraron conglomerados próximos a zonas limítrofes con otros países. $\mathrm{Al}$ interior de los conglomerados, primero se observaron mayores tasas de notificación en población de edad escolar para luego extenderse a población mayor (15-59 años). A partir de 2011, las mayores tasas se observaron en menores de 5 años residentes en el centro del país. Se pudieron caracterizar dos etapas de transmisión espacio-temporal de la gripe $\mathrm{A}(\mathrm{H} 1 \mathrm{~N} 1) \mathrm{pdm} 09$. La primera etapa se caracterizó por altas tasas de notificación y una posible interacción con individuos provenientes de otros países llegados a las grandes ciudades de la Argentina (patrón de jerarquía). La segunda etapa mostró una mayor interacción en algunas zonas fronterizas y sin un patrón claro de jerarquía. Estos resultados plantean la necesidad de generar una mayor coordinación en países del Cono Sur, con el objetivo de implementar políticas más efectivas de prevención y vacunación.

\section{REFERENCES}

1. Alexander FE, Cuzick J. Methods for the assessment of disease clusters. In: Elliott P, Cuzick J, English D, Stern R, editors. Geographical environmental epidemiology. New York: Oxford University Press; 1992. 

133-8, 2015

2. Bandaranayake D, Jacobs M, Baker M, Hunt D, Wood T, Bissielo A, et al. The second wave of 2009 pandemic influenza A (H1N1) in New Zealand, January-October 2010. Euro Surveill. 2011;16:pii=19788.

3. Borja-Aburto VH, Chowell G, Viboud C, Simonsen L, Miller MA, Grajales-Muñiz $\mathrm{C}$, et al. Epidemiological characterization of a fourth wave of pandemic A/H1N1 influenza in Mexico, winter 2011-2012: age shift and severity. Arch Med Res. 2012;43:563-70.

4. Chowell G, Viboud C, Munayco CV, Gómez J, Simonsen L, Miller MA, et al. Spatial and temporal characteristics of the 2009 A/H1N1 influenza pandemic in Peru. PLOS One. 2011;6:e21287.

5. Ellis J, Galiano M, Pebody R, Lackenby A, Thompson C, Bermingham A, et al. Virological analysis of fatal influenza cases in the United Kingdom during the early wave of influenza in winter 2010/11. Euro Surveill. 2011;16:pii=19760.

6. Hu W, Williams G, Phung H, Birrell F, Tong S, Mergensen K, et al. Did socioecological factors drive the spatiotemporal patterns of pandemic influenza A (H1N1)? Environ Int. 2012;45:39-43.

7. Instituto Nacional de Estadística y Censos. Censo 2010. Resultados definitivos. [cited 2013 Jan 15]. Available from: http://www.indec.mecon.gob.ar/

8. Kulldorf M, Heffernan R, Hartman J, Assunção R, Mostashari F. A space-time permutation scan statistic for disease outbreak detection. PLOS Med. 2005;2:e59.

9. Kulldorff M. SaTScan ${ }^{\mathrm{TM}}$ user guide. [cited 2010]. Available from:http://www.satscan. org/

10. Lee SS, Wong NS. The clustering and transmission dynamics of pandemic influenza A (H1N1) 2009 cases in Hong Kong. J Infect. 2011;63:274-80.

11. Lowen AC, Mubareka S, Steel J, Palese P. Influenza virus transmission is dependent on relative humidity and temperature. PLOS Pathog. 2007;3:1470-6.

12. Maliszewski PJ, Wei R. Ecological factors associated with pandemic influenza A (H1N1) hospitalization rates in California, USA: a geospatial analysis. Geospat Health. 2011;6:95-105.
13. Merler S, Ajelli M, Pugliese A, Ferguson NM. Determinants of the spatiotemporal dynamics of the 2009 H1N1 pandemic in Europe: implications for real-time modelling. PLOS Comput Biol. 2011;7:e1002205.

14. Opatowski L, Fraser C, Griffin J, de Silva E, Van Kerkhove MD, Lyons EJ, et al Transmission characteristics of the $2009 \mathrm{H} 1 \mathrm{~N} 1$ influenza pandemic: comparison of 8 southern hemisphere countries. PLOS Pathog. 2011;7:e1002225.

15. Orellano PW, Grassi A, Reynoso JI, Palmieri A, Uez O, Carlino O. Efecto del cierre de las escuelas sobre el brote de influenza A H1N1 en Tierra del Fuego, Argentina. Rev Panam Salud Publica. 2010;27:226-9.

16. Pan American Health Organization. Influenza and other respiratory viruses surveillance, 2010-2013. [cited 2013 Feb 05]. Available from: http://ais.paho.org/ phip/viz/ed_flu.asp

17. Smallman-Raynor M, Cliff AD. Avian influenza A (H5N1) age distribution in humans. Emerg Infect Dis. 2007;13:510-2.

18. Van Kerkhove MD, Mounts AW, Mall S, Vandemaele KA, Chamberland M, dos Santos $\mathrm{T}$, et al. Epidemiologic and virologic assessment of the 2009 influenza A (H1N1) pandemic on selected temperate countries in the southern hemisphere: Argentina, Australia, Chile, New Zealand and South Africa. Influenza Other Respir Viruses. 2011;5:e487-98.

19. Wong NS, Lee SS. The spatiotemporal diffusion of pandemic influenza (H1N1)2009 in Hong Kong. Procedia Environ Sci. 2011;3:26-31.

20. Xiao H, Tian HY, Zhao J, Zhang XX, Li YP, Liu Y, et al. Influenza A (H1N1) transmission by road traffic between cities and towns. Chin Sci Bull. 2011;56:261320.

Received: 20 January 2014

Accepted: 1 July 2014 